\title{
Percutaneous Management of Benign and Postoperative Biliary Strictures
}

\author{
Haibo Shao, $\mathrm{MD}^{1,2}$ Ronald S Arellano, MD ${ }^{2}$ \\ ${ }^{1}$ Department of Interventional Radiology, First Hospital of China \\ Medical University, Shenyang, China \\ 2 Division of Interventional Radiology, Department of Radiology, \\ Massachusetts General Hospital, Harvard Medical School, Boston, \\ Massachusetts
}

\begin{abstract}
Address for correspondence Ronald S. Arellano, MD, Division of Interventional Radiology, Department of Radiology, Massachusetts General Hospital, Harvard Medical School, 55 Fruit Street, GRB 293, Boston, MA 02114 (e-mail: rarellano@mgh.harvard.edu).
\end{abstract}

Dig Dis Interv 2017;1:28-35.

\begin{abstract}
Keywords

- benign biliary stricture

- percutaneous intervention

- biliary obstruction

- biliary stents

Biliary strictures are an uncommon yet challenging clinical problem. They are often iatrogenic in nature, usually the consequence of hepatobiliary surgery. Although the etiology may be benign, the clinical consequences, if unrecognized, can progress to ascending cholangitis, sepsis, and hepatic abscesses. Optimal treatment requires expertise and input from multiple specialties, including gastroenterology, surgery, infectious disease, and interventional radiology. Currently, available interventional techniques play a critical role in the management of patients with benign biliary strictures.
\end{abstract}

Most benign biliary strictures (BBSs) are most commonly iatrogenic in nature and are typically the result of surgical injury. Postoperative strictures can be broadly divided into anastomotic and nonanastomotic strictures according to their anatomic locations. Anastomotic strictures typically develop in patients who have undergone previous hepatobiliary surgery or liver transplantation. Liver transplant patients have a relatively higher incidence of biliary anastomotic stricture than those with other types of abdominal surgeries. ${ }^{1}$

Common etiologies for nonanastomotic BBS include cholangitis, ischemic injury during liver transplantation, and cholelithiasis. Clinical manifestations of BBS include jaundice, fever, elevated levels of serum alkaline phosphatase, and bilirubin. Endoscopic retrograde cholangiopancreatography (ERCP) is recognized as the first-line treatment for $\mathrm{BBS}^{2}$; however, ERCP is not a viable option for patients with Roux-en-Y reconstruction or those with esophageal or upper gastrointestinal obstruction. In these situations, alternative approaches to access the bile ducts are necessary for diagnosis and treatment. ${ }^{3}$

Interventional radiologists play a vital role in the management of BBS by providing image-guided percutaneous transhepatic cholangiography (PTC), catheter insertion, balloon dilation, and stent placement. The purpose of this review is to summarize percutaneous techniques, shortterm and long-term therapeutic effects, complications, and novel techniques for management of BBS.

\section{Percutaneous Transhepatic Cholangiography}

The purpose of PTC is to gain access and evaluate the intrahepatic bile ducts by means of contrast injection. Successful percutaneous puncture into a dilated intrahepatic biliary tree with a fine needle is essential for access to biliary system and subsequent diagnosis and treatment. Needle puncture of dilated bile ducts can be performed using under fluoroscopy, ultrasound, or computed tomography (CT) guidance. Accessing the biliary tree can be challenging in postoperative patients with altered ductal anatomy or reduced liver volume. ${ }^{4}$ Auxiliary techniques to improve access to the biliary tree in cases of altered anatomy have been described. In 1967, opacification of the biliary tree via puncture of the gallbladder was shown to facilitate secondary biliary received

November 14, 2016 accepted after revision January 30, 2017 published online March 14, 2017
Issue Theme Biliary Diseases and Interventions; Guest Editor, Ronald S. Arellano, MD
Copyright $\odot 2017$ by Thieme Medical Publishers, Inc., 333 Seventh Avenue, New York, NY 10001, USA Tel: +1(212) 584-4662.
DOI https://doi.org/ 10.1055/s-0037-1599254. ISSN 2472-8721. 
puncture. ${ }^{5}$ A randomized study comparing CT fluoroscopy with fluoroscopy alone found that CT fluoroscopy combined with fluoroscopy led to higher successful rates of first puncture, fewer punctures, and shorter procedure times. ${ }^{6}$ At times, it may be necessary to access a nondilated biliary system. In these situations, access can often be achieved by directing needle punctures in the vicinity of peripheral branches of the portal vein. In a study evaluating this technique, 35 patients with biliary strictures with nondilated bile ducts, including 24 cases of benign bilioenteric anastomotic strictures, successful access to the biliary tree was achieved in $94.3 \%$ of cases. ${ }^{7}$ This technique is very helpful for the postliver transplantation patients when early biliary strictures are suspected.

PTC can accurately depict the location and characteristics of biliary strictures in most patients. ${ }^{8}$ The appearances and features of BBS in cholangiography can vary depending on the etiology. Most biliary strictures are unifocal and are often iatrogenic (liver transplantation, partial hepatectomy, and bile duct injury). Noniatrogenic causes such as stone disease, pancreatitis, trauma, radiation therapy, portal biliopathy, and idiopathic papillary stenosis can also lead to unifocal strictures. The reasons for multifocal or diffuse bile duct strictures include ischemia (hepatic artery occlusion after liver transplantation) and cholangitis (sclerosing cholangitis, pyogenic cholangitis, tuberculosis, human immunodeficiency virus, parasitosis, autoimmune disease, and immunoglobulin G4-related cholangiopathy). The goals of PTC are to depict the levels of obstruction, evaluate for bile duct stones, define etiologies of cholangitis, and demonstrate bile duct leak. ${ }^{9}$ Additional maneuvers such as catheter drainage, balloon dilation, and stent placement can be performed through PTC access.

\section{Percutaneous Transhepatic Catheter Drainage}

The goal of catheter drainage of the biliary is to relieve jaundice, control infection, and improve nutritional status, which are all essential for patients in the perioperative period. ${ }^{10,11}$ The decision regarding whether to do more invasive manipulations at the time of initial drainage depends on technical challenges or complications during bile duct catheterization. When cholangitis, bleeding, or infection complicate biliary catheterization, or if the puncture has been technically challenging and time consuming, an external biliary drainage catheter should be placed without further attempts to cross the stricture. ${ }^{9}$ Alternatively, if PTC goes smoothly, attempts to cross biliary strictures with guide wires are reasonable. ${ }^{9,12}$ It may not always be easy to cross the strictures by using a conventional 0.035 " guidewire. Fidelman introduced a Lunderquist-Ring Torque guidewire with a "stick" formation at the distal end and a "handle" formed on the proximal end to allow torqueing, which is useful for crossing strictures. ${ }^{9}$ In circumstances of complete biliary occlusion, needle-knife fistulotomy may be considered to re-establish communication between the biliary tree and bowel. ${ }^{13}$
Usually, an external biliary drainage protocol with or without balloon dilation will be undertaken to achieve restoration of biliary patency. ${ }^{10-12,14-18}$ Catheter sizes typically range from 7 to $12 \mathrm{Fr}$ and in some instances can be up sized to 14 to $18 \mathrm{Fr}$. In general, catheter exchange intervals vary from weeks to several months, depending on patient tolerance, physician experience, and evolution of the stricture with catheter drainage. ${ }^{11,12,14,18}$ If follow-up cholangiograms show less than $20 \%$ residual stenosis and flow contrast material into the small bowel within 30 seconds, drainage is considered to be technically successful. Residual stenosis of more than $20 \%$ or drainage of the contrast material into small bowel was more than 30 seconds, drainage catheters should be up sized and internal/external drainage extended for longer periods. ${ }^{19}$ There is no strict time algorithm to determine optimum drainage, but once optimum drainage has been achieved, bilirubin levels have normalized and repeat cholangiography suggests biliary patency, a clamp trial of the catheter can be considered. ${ }^{14}$ Catheters should be removed if the stricture remained patent, or the patients switched to a more invasive solution such as stent placement or surgical revision if catheter drainage and dilatation fail to achieve the desired results. ${ }^{14}$

Recently, large bore catheters of 18 to $20 \mathrm{Fr}$ have been advocated for percutaneous management of BBS, even in postliver transplantation patients. ${ }^{20}$ The use of the large bore catheters showed promising rates of stricture resolution; however, this was often achieved at the expense of negative impact on patients' quality of life by extending catheterization time and increasing numbers of interventions. ${ }^{20,21}$ Dual catheter techniques, whereby two catheters are placed via a single puncture site, may offer the ability to achieve optimum drainage with fewer interventions compared with other techniques. Gwon et al described insertion of an 8.5Fr catheter through the lumen of a 14-Fr catheter and then both catheters across the stricture to achieve a diameter of $22.5 \mathrm{Fr}$ at the stricture site but kept $14 \mathrm{Fr}$ at the puncture site. $^{16}$

One of the challenges of percutaneous biliary drainage can be patient discomfort at the puncture site. This is most commonly encountered with right-sided drainage. For the reason, left-sided punctures are often better tolerated than right-sided drainage and are prefers when the anatomy allows. ${ }^{14}$ Also, specially designed skin anchoring devices may also improve the quality of life for those who require long-term drainage. ${ }^{22}$

\section{Balloon Dilation}

Selection of balloon size should be estimated based on the cholangiogram. Initially, a balloon size slightly less than or equal to bile duct diameter adjacent to the stricture is recommended for initial dilatation to minimize the risk of anastomotic disruption and bile leak. If necessary, larger diameter balloons can be used for subsequent dilations with balloon sizes up to 25 to $30 \%$ larger than the estimated diameter of the duct being dilated. ${ }^{12,19}$ Most balloon sizes for BBS range from 4 to $12 \mathrm{~mm} .^{10-12,14-18}$ Common bile duct 
strictures can be safely dilated to 10 to $12 \mathrm{~mm}$ in an adult. Smaller balloons (4-8 $\mathrm{mm}$ ) may be necessary for lobar ducts and for the biliary strictures in children., ${ }^{9,23}$ Time intervals between balloon dilations range from 1 to 2 weeks to every 3 months to establish and maintain duct patency. ${ }^{17,18}$ An- gioplasty balloon catheters should always be inflated gradually until the site of narrowing, commonly referred as the "waist" is eliminated (-Fig. 1). Satisfactory dilation is marked by disappearance of the "waist" and restoration of normal bile flow. ${ }^{24}$
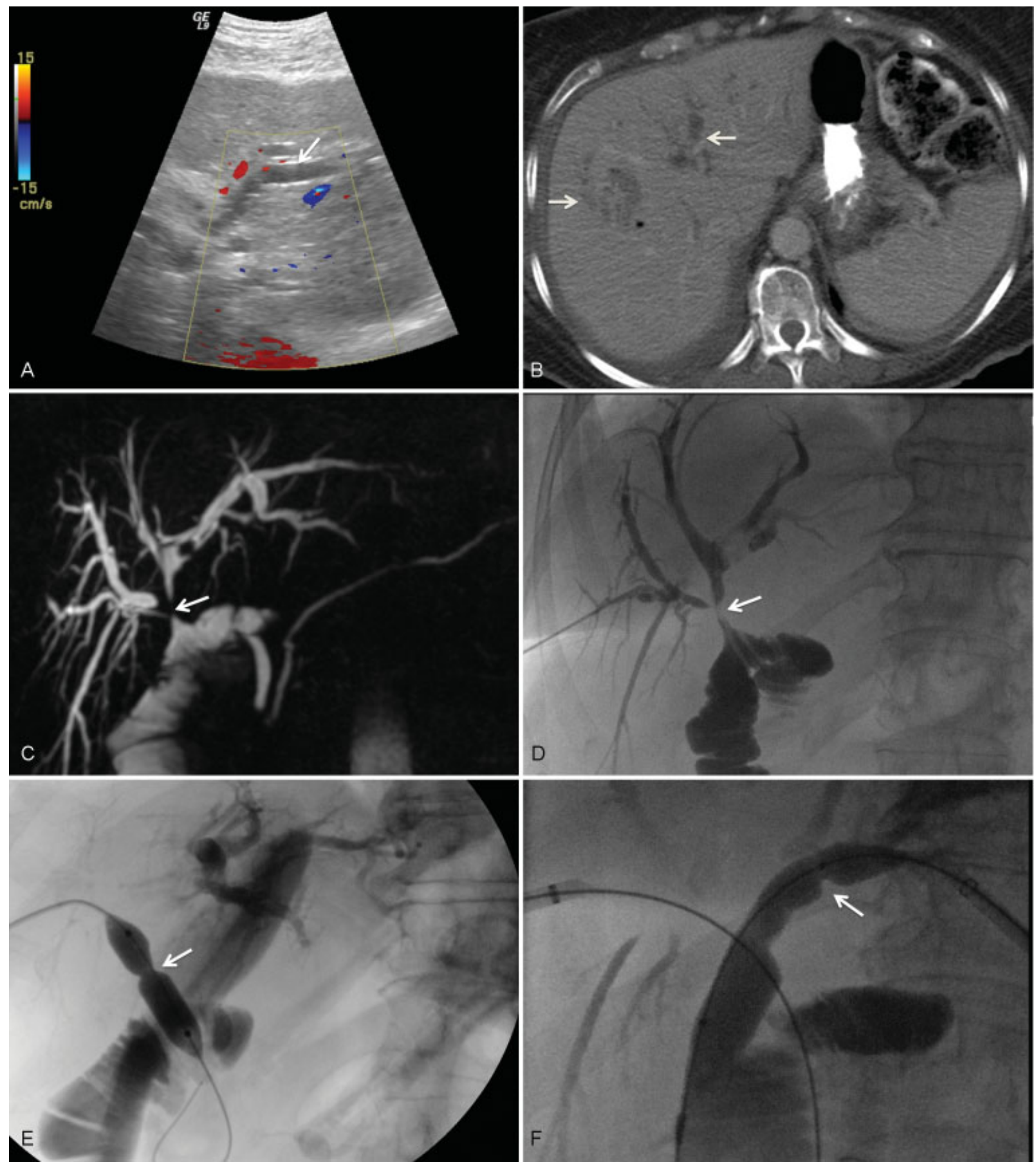

Fig. 1 (A) Color Doppler ultrasound image of a 63-year-old patient s/p complicated cholecystectomy that demonstrates dilated intrahepatic bile duct (white arrow). (B) Axial contrast material-enhanced CT image that demonstrates dilated biliary branches in left and right hepatic lobes (white arrows). (C) MRCP that demonstrates bilioenteric anastomosis stenosis (white arrow). (D) Percutaneous transhepatic cholangiogram that demonstrates dilated bile ducts and anastomotic stricture. (E) Balloon dilation of the anastomotic stricture from a percutaneous right duct approach. "Waist" (white arrow) indicates site of stricture. (F). Balloon dilation of left biliary stricture that demonstrates "waist" (white arrow). (G) Postprocedure cholangiogram that demonstrates $12 \mathrm{~F}$ catheters placed across the bilioenteric anastomosis via left and right ducts. (H) Transhepatic cholangiogram 3 months after balloon dilation and continuous drainage shows resolution of anastomotic stricture and widely patent anastomosis (white arrow). The catheters were removed after cholangiography. (I) Axial contrast material-enhanced CT 6 months after catheter removal shows decompressed bile ducts. CT, computed tomography; MRCP, magnetic resonance cholangiopancreatography. 

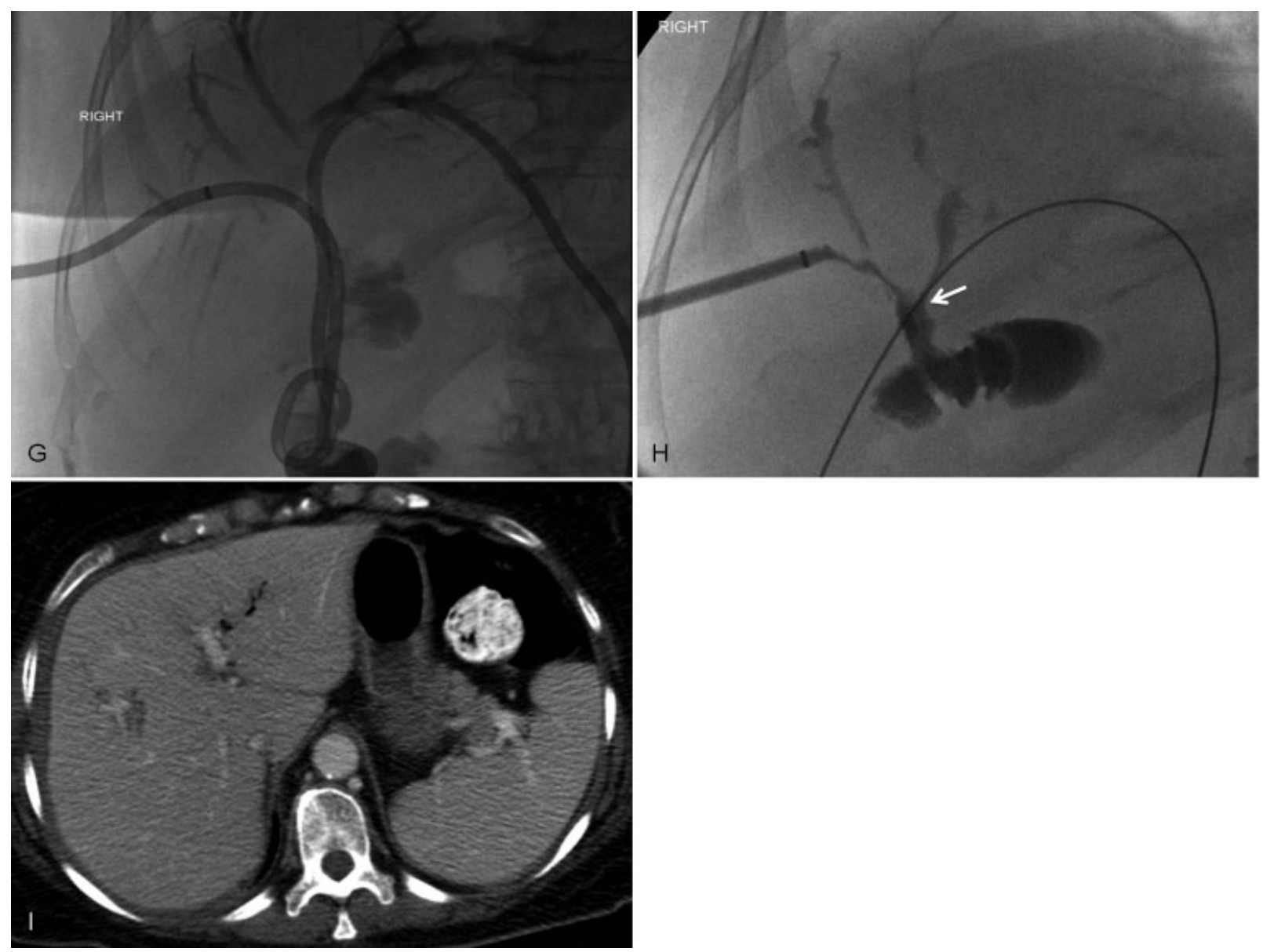

\section{Long-Term Results of Catheterization and Balloon Dilation}

From 2007 to present, eight studies with the mean follow-up time of 34 months to 5.2 years have evaluated the long-term results of balloon dilatation. ${ }^{10-12,14-18}$ Most have showed 1 -year patency rates of 94 to $100 \%$, while 3-year patency rates range from 71 to $96 \% .^{10-12,15,16,18}$ The 5- and 10-year patency rates were 74 to 88 and 67 to $72 \%$, respectively, in two recent studies. ${ }^{12,14}$ However, a retrospective study with 25 -year results showed a lower long-term patency of 52, 49, and $41 \%$ in 5,10 , and 25 years, respectively. ${ }^{17}$ The long-term results of catheterization and balloon dilation are listed in -Table 1.

Kucukay et al found that there was no difference in longterm patency between patients who underwent successful one-time balloon dilation versus those with successful initial dilatation and two or more subsequent dilations (85.4 vs. $87.9 \%$ ). As a result, repeated balloon dilation is not recommended when the first procedure is successful. ${ }^{24}$ Furthermore, Janssen et al found that restenosis and treatment failure occurred more often in patients who underwent multiple dilatations. They found that factors that led clinically relevant restenosis were the number of strictures and the number of treatments. ${ }^{12}$ Between strictures at anastomotic and nonanastomotic sites, Cantwell et al revealed that no significant difference was found in the rate of clinically significant restenosis after the first treatment. ${ }^{17}$ Regarding the patients with orthotopic liver transplantation (OLT), the risk of stricture recurrence for those with no history of OLT was found to be lower than that for patients with a history of OLT. ${ }^{14}$

\section{Biliary Stents}

Self-expandable metallic stent (SEMS) provides an optional solution for refractory or recurrent BBS, especially when patients are unsuitable or unwilling to undergo surgery. ${ }^{29,30}$ However, the use of SEMS for BBS remains controversial at present because of the high rate of stent obstruction secondary to epithelial hyperplasia. ${ }^{31}$ Furthermore, stent removal 


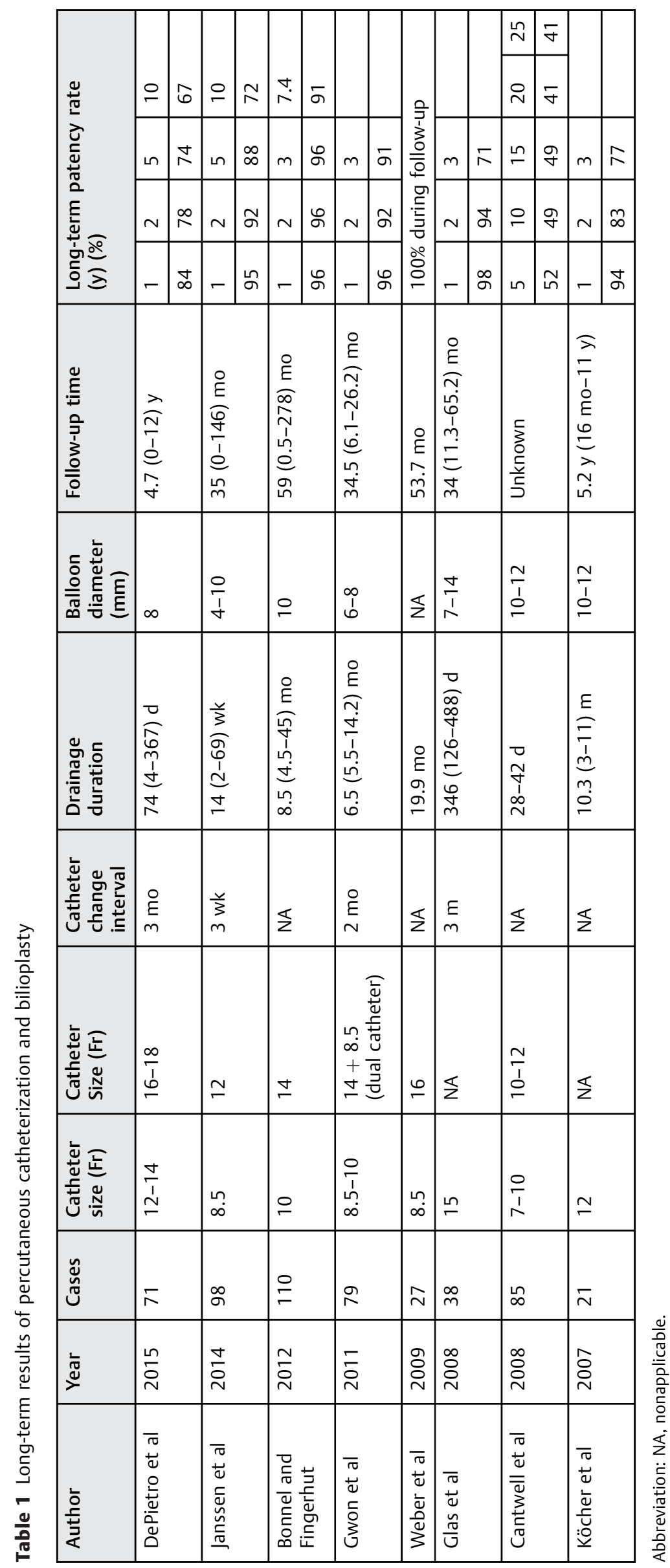


may be difficult or impossible once they become embedded in the wall due to epithelial hyperplasia. ${ }^{32}$

The introduction of fully covered SEMS (FCSEMS) offers solutions to overcome these limitations. Covered metal stents have a metallic skeleton covered by a biocompatible, layer of synthetic material which is resistant to the effects of bile, gastric, and pancreatic secretions. The covered layer prevents the stent from becoming embedded and makes stent very smooth and easy to remove. ${ }^{33,34}$ In addition, FCSEMS can be implanted and removed by either endoscopic or percutaneous methods. Gwon et al reported 68 cases of BBS treated with percutaneously placed FCSEMS and showed technical success of $98.5 \%$ (67/68) for stent placement and $98.5 \%$ (66/67) for stent removal. ${ }^{35}$ After a mean stent indwelling period of 5.8 months and mean follow-up period of 36 months, the primary patency rates at 1, 2, 3, 4, and 5 years reached $91,89,76,68$, and $68 \%$, respectively. ${ }^{35}$ Another function of FCSEMS is to block the bile leaks, especially for the bilioenteric anastomotic strictures combined with leakage. Gwon et al reported $100 \%$ clinical success of 11 cases of postoperative bile leaks treated with retrievable FCSEMS. ${ }^{36}$ Recently, multicenter clinical trials showed that endoscopic placed FCSEMS was safe and effective for BBS. ${ }^{37,38}$ Although FCSEMSs are effective in minimizing endothelial overgrowth, their smooth surfaces may contribute to stent migration which is reportedly as high rate as $16.2 \%{ }^{35}$

The application of biodegradable stents in BBS may help overcome the migration problems associated with FCSEMS. The currently available biodegradable biliary stent is made of polydioxanone, which is proved by the Food and Drug Administration as a biodegradable material for clinical use. Delivery systems range in diameter from 11 to $15 \mathrm{Fr}$ and the degradation time, which occurs by hydrolytic processes, is approximately 3 to 6 months. ${ }^{39,40}$ Recently, Mauri et al reported a multicenter clinical study of percutaneously implanted of biodegradable stents for 107 patients with refractory BBS. The technical success was $98 \%$. Stent migration was observed only in $2 / 107$ cases (2\%). The stricture recurrence rates at 1,2 , and 3 years were $7.2,26.4$, and $29.4 \%$, respectively. Although they reported no major complications, restenosis was found to be associated with subsequent cholangitis and biliary stones. ${ }^{41}$

\section{Other Percutaneous Techniques for Management of Benign Biliary Strictures}

\section{Magnetic Compression Anastomosis}

Magnetic compression anastomosis (MCA) is a technique whereby a pair of cylindrical samarium-cobalt magnets that measure $4 \times 10 \mathrm{~mm}$ are used to treat high grade or complete biliary strictures. Two magnets are introduced by percutaneous and endoscopic access separately and approximate each other on different sides of the stricture. Compression by the approximated magnets caused ischemic necrosis of the tissue between the magnets, forming a fistula. Jang et al reported their clinical effectiveness treating both biliobiliary and bilioenteric anastomoses. ${ }^{42,43}$

\section{Percutaneous Transhepatic Cholangioscopy}

Percutaneous transhepatic cholangioscopy (PTCS) offers the option of direct endoluminal visualization of the biliary tree for diagnostic and therapeutic interventions. ${ }^{44}$ Biliary stones are the most commonly encountered disorder with biliary strictures. Treatment of BBS can be difficult in the setting of choledocholithiasis. Percutaneous transhepatic endoscopic biliary holmium laser lithotripsy (PTBL) can be helpful in this setting. Rimon et al reported a group of patients with biliary stones who failed conventional treatment that were treated with PTBL. In 6/22 patients with stone disease in the setting of biliary strictures, PTBLs were able to achieve complete fragmentation of the stones with no major complication occurred. ${ }^{45}$

\section{Percutaneous Transjejunal Biliary Intervention}

Percutaneous transjejunal biliary intervention (PTJBI) is an alternative technique for access to the biliary system to treat benign biliary diseases in patients with a Roux-en-Y hepaticojejunostomy. Fontein et al reported the largest series that evaluated efficacy of PTJBI for BBS and stone retrieval. In this procedure, the Roux loop is punctured under fluoroscopic guidance, using surgical clips as a landmark, and a guidewire advanced into the afferent limb. Then, an 8- to $10-\mathrm{Fr}$ sheath is advanced over the guidewire into the afferent limb, thus providing access to biliary strictures and stones if a guidewire crosses the hepaticojejunal anastamosis. ${ }^{46}$ Mansueto et al treated a group of patients with hepaticojejunostomy dehiscence in which initial access to the biliary tree was achieved by PTJBI, followed by a rendezvous technique to establish percutaneous biliary drainage to the jejunum. ${ }^{47}$

\section{Complications}

Hemorrhage and infection represent the most commonly encountered complications of percutaneous biliary interventions. An analysis of 419 cases of percutaneous transhepatic biliary drainages indicated an overall complication rate of $9.31 \%$, including bleeding (2.86\%), cholangitis (1.67\%), and sepsis (1.43\%). ${ }^{48}$ Transarterial embolization is an effective management for bleeding associated with active extravasation or pseudoaneurysm of the hepatic artery. ${ }^{15,17,49}$ Biliary leak and bilomas are less frequently encountered and can usually be managed by drainage. ${ }^{50}$

Drainage-related complications are reported as high as $21.4 \%$, including occlusion, dislocation, and cholangitis. ${ }^{51}$ Stent-related complications include stent migration and perforation..$^{52}$ Procedure-related mortality was reported as $2 \%$. Multivariate analysis revealed this was related to the preprocedure presence of ascites, high C-reactive protein, and a high white cell count. ${ }^{53}$

\section{Conclusion}

Percutaneous transhepatic interventions play an important role in the treatment of benign or postoperative biliary strictures, especially for those that are inaccessible by endoscopic techniques. Treatment can be accomplished by one of 
several interventional techniques. Catheterization and balloon dilation are the primary recommended methods for treating BBS, with the satisfactory long-term results. Newer techniques, such as SEMSs, fully covered, and biodegradable stents are options when strictures are refractory treatment or fail to resolve by conventional methods. Innovative and novel techniques such as MCA, PTCS, and PTJBI may be helpful in the management of BBS. However large, multicenter, randomized contrast clinical trials are necessary to further evaluate their long-term efficacy and safety.

\section{Conflict of Interest}

None.

\section{References}

1 Chang JH, Lee I, Choi MG, Han SW. Current diagnosis and treatment of benign biliary strictures after living donor liver transplantation. World J Gastroenterol 2016;22(4):1593-1606

2 Baron TH Sr, Davee T. Endoscopic management of benign bile duct strictures. Gastrointest Endosc Clin N Am 2013;23(2):295-311

3 Hung HH, Chen TS, Tseng HS, et al. Percutaneous transhepatic cholangiography and drainage is an effective rescue therapy for biliary complications in liver transplant recipients who fail endoscopic retrograde cholangiopancreatography. J Chin Med Assoc 2009;72(8):395-401

4 Morita S, KitanosonoT, Lee D, et al. Comparison of technical success and complications of percutaneous transhepatic cholangiography and biliary drainage between patients with and without transplanted liver. AJR Am J Roentgenol 2012;199(5):1149-1152

5 DeMasi CJ, Akdamar K, Sparks RD, Hunter FM. Puncture of the gallbladder during percutaneous transhepatic cholangiograhy. JAMA 1967;201(4):225-228

6 Laufer U, Kirchner J, Kickuth R, Adams S, Jendreck M, Liermann D. A comparative study of CT fluoroscopy combined with fluoroscopy versus fluoroscopy alone for percutaneous transhepatic biliary drainage. Cardiovasc Intervent Radiol 2001;24(4): 240-244

7 Shimizu H, Kato A, Takayashiki T, et al. Peripheral portal veinoriented non-dilated bile duct puncture for percutaneous transhepatic biliary drainage. World J Gastroenterol 2015;21(44): 12628-12634

8 Fidelman N, Kerlan RK Jr, Laberge JM, Gordon RL. Accuracy of percutaneous transhepatic cholangiography in predicting the location and nature of major bile duct injuries. J Vasc Interv Radiol 2011;22(6):884-892

9 Fidelman N. Benign biliary strictures: diagnostic evaluation and approaches to percutaneous treatment. Tech Vasc Interv Radiol 2015;18(4):210-217

10 Weber A, Prinz C, Gerngross C, et al. Long-term outcome of endoscopic and/or percutaneous transhepatic therapy in patients with biliary stricture after orthotopic liver transplantation. J Gastroenterol 2009;44(12):1195-1202

11 Glas L, Courbière M, Ficarelli S, Milot L, Mennesson N, Pilleul F. Long-term outcome of percutaneous transhepatic therapy for benign bilioenteric anastomotic strictures. J Vasc Interv Radiol 2008;19(9):1336-1343

12 Janssen JJ, van Delden OM, van Lienden KP, et al. Percutaneous balloon dilatation and long-term drainage as treatment of anastomotic and nonanastomotic benign biliary strictures. Cardiovasc Intervent Radiol 2014;37(6):1559-1567

13 Lim JU, Joo KR, Cha JM, et al. Needle-knife fistulotomy with percutaneous transhepatic cholangioscopy for managing com- plete bilioenteric anastomosis occlusion. Surg Laparosc Endosc Percutan Tech 2014;24(1):e10-e12

14 DePietro DM, Shlansky-Goldberg RD, Soulen MC, et al. Long-term outcomes of a benign biliary stricture protocol. J Vasc Interv Radiol 2015;26(7):1032-1039

15 Bonnel DH, Fingerhut AL. Percutaneous transhepatic balloon dilatation of benign bilioenteric strictures: long-term results in 110 patients. Am J Surg 2012;203(6):675-683

16 Gwon DI, Sung KB, Ko GY, Yoon HK, Lee SG. Dual catheter placement technique for treatment of biliary anastomotic strictures after liver transplantation. Liver Transpl 2011;17(2):159-166

17 Cantwell CP, Pena CS, Gervais DA, Hahn PF, Dawson SL, Mueller PR. Thirty years' experience with balloon dilation of benign postoperative biliary strictures: long-term outcomes. Radiology 2008; 249(3):1050-1057

18 Köcher M, Cerná M, Havlík R, Král V, Gryga A, Duda M. Percutaneous treatment of benign bile duct strictures. Eur J Radiol 2007; 62(2):170-174

19 Choo SW, Shin SW, Do YS, et al. The balloon dilatation and large profile catheter maintenance method for the management of the bile duct stricture following liver transplantation. Korean J Radiol 2006;7(1):41-49

20 Ludwig JM, Webber GR, Knechtle SJ, Spivey JR, Xing M, Kim HS. Percutaneous management of benign biliary strictures with large-bore catheters: comparison between patients with and without orthotopic liver transplantation. J Vasc Interv Radiol 2016;27(2):219-225.e1

21 Mauri G, Criado E. Percutaneous management of benign biliary strictures: is it time to focus on reducing procedure invasiveness? J Vasc Interv Radiol 2016;27(6):934-936

22 Nyman R, Eklöf H, Eriksson LG, et al. Soft-tissue-anchored transcutaneous port for long-term percutaneous transhepatic biliary drainage. Cardiovasc Intervent Radiol 2005;28(1):53-59

23 Fonio P, Calandri M, Faletti R, et al. The role of interventional radiology in the treatment of biliary strictures after paediatric liver transplantation. Radiol Med (Torino) 2015;120(3):289-295

24 Kucukay F, Okten RS, Yurdakul M, et al. Long-term results of percutaneous biliary balloon dilation treatment for benign hepaticojejunostomy strictures: are repeated balloon dilations necessary? J Vasc Interv Radiol 2012;23(10):1347-1355, quiz 1357

25 Mukund A, Rajesh S, Agrawal N, Arora A, Arora A. Percutaneous management of resistant biliary-enteric anastomotic strictures with the use of a combined cutting and conventional balloon cholangioplasty protocol: a single-center experience. J Vasc Interv Radiol 2015;26(4):560-565

26 Kakani NK, Puckett M, Cooper M, Watkinson A. Percutaneous transhepatic use of a cutting balloon in the treatment of a benign common bile duct stricture. Cardiovasc Intervent Radiol 2006; 29(3):462-464

27 Saad WE, Davies MG, Saad NE, et al. Transhepatic dilation of anastomotic biliary strictures in liver transplant recipients with use of a combined cutting and conventional balloon protocol: technical safety and efficacy. J Vasc Interv Radiol 2006;17(5):837-843

28 Atar E, Bachar GN, Bartal G, et al. Use of peripheral cutting balloon in the management of resistant benign ureteral and biliary strictures. J Vasc Interv Radiol 2005;16(2 Pt 1):241-245

29 Lopez RR Jr, Cosenza CA, Lois J, et al. Long-term results of metallic stents for benign biliary strictures. Arch Surg 2001;136(6):664-669

30 Maccioni F, Rossi M, Salvatori FM, Ricci P, Bezzi M, Rossi P. Metallic stents in benign biliary strictures: three-year follow-up. Cardiovasc Intervent Radiol 1992;15(6):360-366

31 Yoon HK, Sung KB, Song HY, et al. Benign biliary strictures associated with recurrent pyogenic cholangitis: treatment with expandable metallic stents. AJR Am J Roentgenol 1997;169(6):1523-1527

32 Shimizu H, Kimura F, Yoshidome H, et al. Surgical management of occluded biliary expandable metallic stent for benign stricture of bilioenteric anastomosis: usefulness of anterior transhepatic procedure. Hepatogastroenterology 2009;56(89):50-53 
33 Abu-Wasel B, Keough V, Renfrew PD, Molinari M. Biliary stent therapy for dominant strictures in patients affected by primary sclerosing cholangitis. Pathobiology 2013;80(4):182-193

$34 \mathrm{Kim} \mathrm{JH}$, Gwon DI, Ko GY, et al. Temporary placement of retrievable fully covered metallic stents versus percutaneous balloon dilation in the treatment of benign biliary strictures. J Vasc Interv Radiol 2011;22(6):893-899

35 Gwon DI, Ko GY, Ko HK, Yoon HK, Sung KB. Percutaneous transhepatic treatment using retrievable covered stents in patients with benign biliary strictures: mid-term outcomes in 68 patients. Dig Dis Sci 2013;58(11):3270-3279

36 Gwon DI, Ko GY, Sung KB, Kim JH, Yoon HK. Percutaneous transhepatic treatment of postoperative bile leaks: prospective evaluation of retrievable covered stent. J Vasc Interv Radiol 2011;22(1): 75-83

37 Coté GA, Slivka A, Tarnasky P, et al. Effect of covered metallic stents compared with plastic stents on benign biliary stricture resolution: a randomized clinical trial. JAMA 2016;315(12): 1250-1257

38 Saxena P, Diehl DL, Kumbhari V, et al. A US multicenter study of safety and efficacy of fully covered self-expandable metallic stents in benign extrahepatic biliary strictures. Dig Dis Sci 2015;60(11):3442-3448

39 Ping Ooi C, Cameron RE. The hydrolytic degradation of polydioxanone (PDSII) sutures. Part I: morphological aspects. J Biomed Mater Res 2002;63(3):280-290

40 Ping Ooi C, Cameron RE. The hydrolytic degradation of polydioxanone (PDSII) sutures. Part II: micromechanisms of deformation. J Biomed Mater Res 2002;63(3):291-298

41 Mauri G, Michelozzi C, Melchiorre F, et al. Benign biliary strictures refractory to standard bilioplasty treated using polydoxanone biodegradable biliary stents: retrospective multicentric data analysis on 107 patients. Eur Radiol 2016;26(11): 4057-4063

42 Jang SI, Choi J, Lee DK. Magnetic compression anastomosis for treatment of benign biliary stricture. Dig Endosc 2015;27(2): 239-249
43 Jang SI, Rhee K, Kim H, et al. Recanalization of refractory benign biliary stricture using magnetic compression anastomosis. Endoscopy 2014;46(1):70-74

44 Ahmed S, Schlachter TR, Hong K. Percutaneous transhepatic cholangioscopy. Tech Vasc Interv Radiol 2015;18(4):201-209

45 Rimon U, Kleinmann N, Bensaid P, et al. Percutaneous transhepatic endoscopic holmium laser lithotripsy for intrahepatic and choledochal biliary stones. Cardiovasc Intervent Radiol 2011; 34(6):1262-1266

46 Fontein DB, Gibson RN, Collier NA, et al. Two decades of percutaneous transjejunal biliary intervention for benign biliary disease: a review of the intervention nature and complications. Insights Imaging 2011;2(5):557-565

47 Mansueto G, Contro A, Zamboni GA, De Robertis R. Retrograde percutaneous transjejunal creation of biliary neoanastomoses in patients with complete hepaticojejunostomy dehiscence. J Vasc Interv Radiol 2015;26(10):1544-1549

48 Weber A, Gaa J, Rosca B, et al. Complications of percutaneous transhepatic biliary drainage in patients with dilated and nondilated intrahepatic bile ducts. Eur J Radiol 2009;72(3):412-417

49 L'Hermine C, Ernst O, Delemazure O, Sergent G. Arterial complications of percutaneous transhepatic biliary drainage. Cardiovasc Intervent Radiol 1996;19(3):160-164

50 Huang SY, Philip A, Richter MD, Gupta S, Lessne ML, Kim CY. Prevention and management of infectious complications of percutaneous interventions. Semin Intervent Radiol 2015;32(2): $78-88$

51 Nennstiel S, Weber A, Frick G, et al. Drainage-related complications in percutaneous transhepatic biliary drainage: an analysis over 10 years. J Clin Gastroenterol 2015;49(9):764-770

52 Bakhru MR, Kahaleh M. Expandable metal stents for benign biliary disease. Gastrointest Endosc Clin N Am 2011;21(3): 447-462, viii

53 Tapping CR, Byass OR, Cast JE. Percutaneous transhepatic biliary drainage (PTBD) with or without stenting-complications, re-stent rate and a new risk stratification score. Eur Radiol 2011;21(9): 1948-1955 